Int. J. Speleol., 13 (1983), pp. 31-41.

\title{
Environmental Implications of Competitive Growth Fabrics in Stalactitic Carbonate
}

\author{
Paul L. Broughton *
}

SUMMARY

\begin{abstract}
Competitive growth fabrics in stalactitic carbonate are not as widespread as commonly supposed. Most radial columnar crystals are attributed to the coalescence of a precursor crystallite mosaic comprised of syntaxial overgrowths. This secondary fabric is the consequence of carbonate precipitation from a thin water film. Competitive growth, however, is much rarer and arises from two contrasting environments: an influx of detritus interrupting carbonate precipitation, and cave flooding. Thick layers of impurities favour deposition of randomly oriented seed crystals on the growth surface. These result in competitive growth centres when the renewal of carbonate precipitation fails to have crystallographic allegience to the substrate. Competitive growth centers resulting in regularly spaced stellate arrays are favoured habits of fibrous aragonite. Competitive growth in calcite is more likely with conditions of cave flooding, when normal growth of syntaxial overgrowths is suppressed. This results in competitive growth between large terminations with planar faces.
\end{abstract}

\section{INTRODUCTION}

Most vadose stalactitic carbonate is composed of columnar calcite crystals in a radial fabric. The traditionally accepted origin of such fabric was summarized by Prinz (1906), reiterated and popularized by Moore (1962) and states that, following interruption of stalactite growth, innumerable tiny calcite crystals are deposited on the stalactite surface. Competitive crystal growth between these randomly-oriented seed crystals re* Present Address: Home Oil Company, 1700 Home Oil Tower, 324-8 Avenue,
S.W., Calgary, Alberta, Canada. 
sults in formation of distinctive radial-columnar mosaics. Recent investigations by Broughton and Kendall (1975), and Kendall and Broughton $(1977,1978)$ have reinterpreted the normal growth fabric, not be to competitive between seed crystals, but a secondary fabric arising from coalescence of precursor syntaxial overgrowths. Only a minority of stalactites have some growth layers composed of crystals with clear evidence of competitive growth. This paper examines the evidence for such competitive growth as a primary fabric, not as the ubiquitous fabric it was once considered, but as a consequence of a restricted depositional environment.

\section{MATERIALS}

This study is based upon 174 thin sections cut from approximately 150 stalactite, stalagmites and a few travertine specimens. Most of these samples lack specific locations, and in any case, the accuracy of such locations could not be assessed. The samples were submitted from various museum and private collections and from caves being destroyed by quarrying operations. Some locality data is known for the specimens figured in this paper. However, it is not considered important, and interpretations arising from this research should not be restricted to this specific material.

\section{NOMENCLATURE}

The nomenclature used in this paper is adapted from that standardized in Kendall and Broughton (1978). The term acicular is used to describe jcrystalline materials that are needlelike, markedly elongate and pointed, and less than 10 microns wide. The termt in independent of mode of packing and thus includes materials described as fibrous (closely packed acicular) or spherulitic (radiating, closely-packed acicular). Columnar is used to describe elongate crystals greater than $10 \mathrm{mi}$ crons in width. The ambiguous term subcrystal is used partially synonymous with domain. It is a crystal subdivision recognized optically by its uniform extinction. Syntaxial overgrowth crystallites (often referred to as subcrystals) are designated as such because carbonate deposited on a portion of the crystal's 
growing surface is separated from other parts by possession of discrete crystal faces. The latter often give rise to the former, but is not commonly the case in stalactitic carbonate .

Moore (1962) suggested that the ubiquitous radial-columnar mosaics in stalactites result from a process of competitive growth between crystals.

This should be recognized by the following:

1. Differentially-oriented crytals having competed for growth space.

2. Crystals in contact with each other along planar boundaries. These compromise boundaries (Buckley, 1951) enlarge as each crystal grows. The orientation of the planar boundary is dependent upon the growth rates of the two crystal faces that are growing towards and against each other, and the angle between them (Bathurst, 1971, p. 422-3; Kendall and Broughton, 1978).

3. Uniform precipitation of carbonate between competitive growth centres results in a crystal boundary oriented normal to the surface between similarly oriented crystals. Boundaries between crystals will be commonly inclined with respect to the substrate surface when the crystal with the faster-growing (or more favcurably-oriented) face adjacent to the common boundary expands at the expense of the less-favoured crystal.

4. Uniform growth on the stalactite surface tends to favour a regûlarly ordered arrangement of nucleation centres.

In speleothems compcsed of columnar calcite (normal growth), the columnar crystals do not interfer with each other. Boundaries between the columnar crystals in most radial-columnar fabric are jagged, serrated or otherwise non-planar.

Inclusions in the columnar calcite mosaic are an important characteristic that suggests a secondary origin. Most inclusions are fluid-filled cavities, and growth lines are defined as arrays of parallel, linear inclusions. The inclusion-defined growth layers are interpreted to have been formed when there was incomplete lateral coalescence of numerous syntaxial overgrowth crystallites. These crystallites coalesce immediately behind the growing surface. This was possible because each crystallite is a syntaxial overgrowth and has near-identical lattice continuity with its neighbours and with the substrate. Complete coalescence necessitates the obliteration of all the inter-crystallite space by lateral rrystallite growth. This generates inclusionfree areas of clear columnar crystal. Less than perfect coalescence allows portions of the water film to be trapped between the crystallite faces, giving rise to inclusions characteristic of growth layer «bands». The deposited carbonate assumes an acicular habit when there is little or no coalescence between the crystallite overgrowths. 
Grain boundaries are related to syntaxial overgrowths on a curved growth surface in a manner peculiar to stalactitic carbonate. Lattice mismatch between the numerous terminations along such a growth surface necessitates a boundary when the slight deviations in lattice orientation cannot be accomodated within planes of dislocations. Brush extinction and other characteristics of lattice distortion (subcrystals, domains, etc.) within columnar crystals are not characteristics of primary fabrics suggesting competitive growth. See discussion on the origins of lattice curvature in stalactitic carbonate by Broughton (1983 a, b) .

\section{COMPETITIVE GROWTH IN STAIACTITIC CARBONATE}

Competitive crystal growth fabrics are generally recognized by decreasing number of crystals in the growth direction and an increasing perfection of the preferred dimensional and crystallographic orientation of crystals away from the layer's origin. These characteristics suggest that columnar crystals which arise from competitive growth act as individuals at the growth surface: their boundaries are related to the growth of the individual columnar crystal in relationship to its neighbour, and not to a precursor fabric.

Many aragonite crystal growth layers are composed of acicular to bladed crystals that exhibit characteristics of competitive growth. Layers of this type commonly overlie zones containing abundant impurities and evidently were seeded from these former surfaces in the manner suggested by Moore (1962). Figure 1 illustrates cross-sections of spherulic growth centres of bladed aragonite. The growth centres are in a layer of randomly oriented crystal mush above a thick deposit of iron oxides. Unlike normal radial fabric growth, the younger growth layers are not crystallographically related to the substrate because the impurity is sufficiently thick to terminate and preserve the underlying bladed crystals. These spherulitic modes are elongated normal to the growth surface, and planar boundaries arise between bladed crystal of adjacent growth centres (with some interpenetration suggesting loose packing).

Uniform carbonate precipitation on the growth surface results in a regular array of growth centres when competitive growth between the seed crystals is favoured. Examples of this are common to the aragonite polymorph, both fibrous (Fig. 2) and more blacied acicular crystals (Fig. 1). 

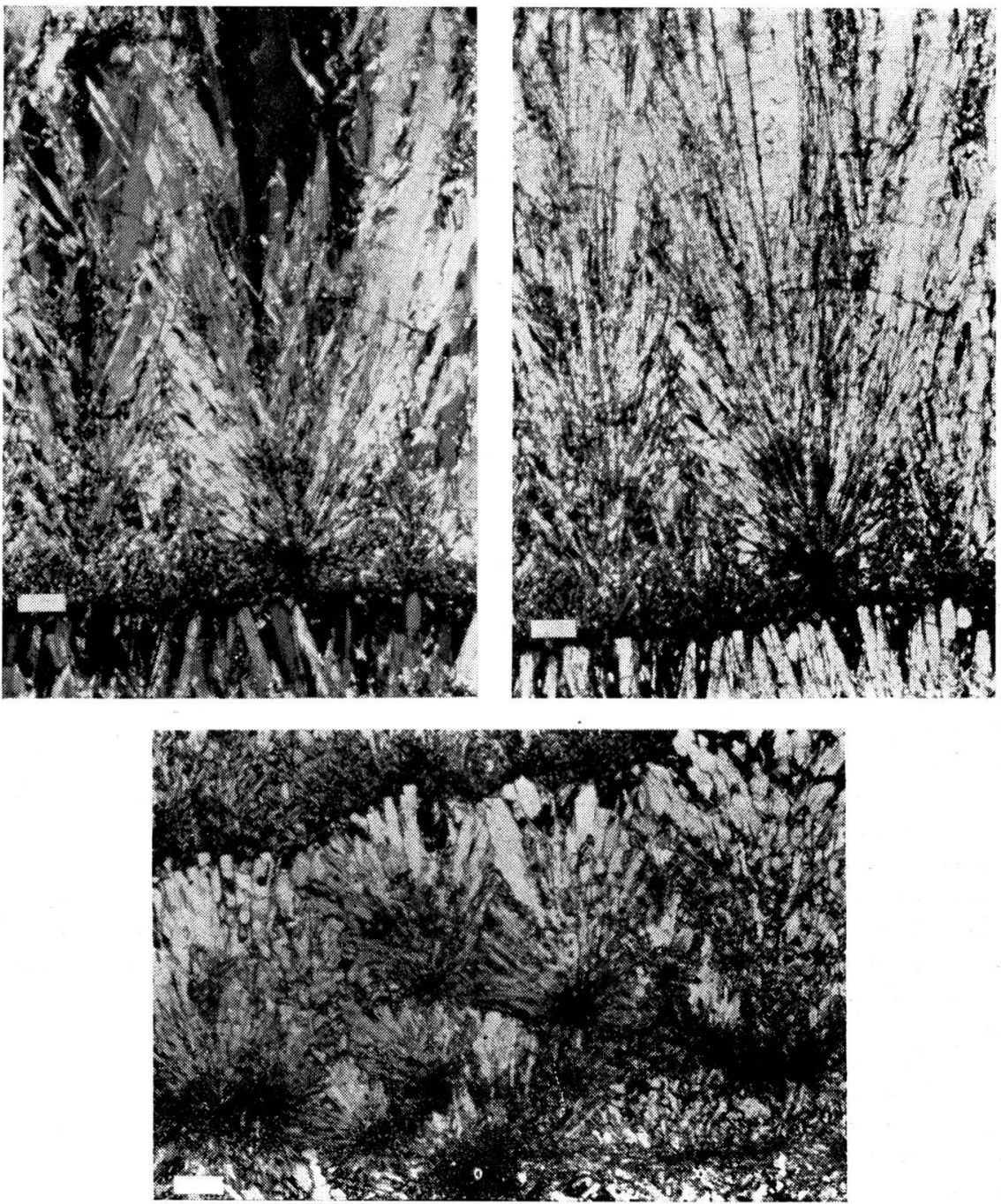

Figure 1. Competitive growt in a crystal mush resulting in fan-shaped to spherulitic sprays of bladed aragonite crystals above a layer of iron oxides. Note the interpenetration between adjacent aggregates in the upper figures (upper left is cross-polarized and upper right is plane polarized light photomicrographs). The lower figure is a cross-section through a cluster of bladed aragonite spherulites comprising a thick layer, suggesting an array of nucleation centres arising from competitive growth (plane polarized light). The stalactite specimen is from the Black Hills, South Dakota. Bar scales are $0.3 \mathrm{~mm}$. 


\section{COMPETITIVE GROWTH AND POLYMORPH}

Competitive growth in stalactitic carbonate is more commonly associated with aragonite than calcite. Both polymorphs are recognized in drusy or coarser spar fabrics having competitive growth fabrics. However, fabrics consisting of acicular to fibrous aragonite are suggested to be almost certainly the result of competitive growth, whereas acicular calcite mosaics are more likely to result from the failure of syntaxial overgrowths to coalesce. Consequently, acicular calcite may pass, by loss of acicular boundaries, into columnar calcite crystals containing similarly oriented linear inclusions. Ccmpetitive growth between calcite crystals is suggested for some growth layers that resemble «normal secondary» or para-axial (Bathurst, 1964, p. 359) cements. However, such a drusy fabric is commonly in lattice continuity with columnar crystals in the younger growth layers characterized by parallel linear inclusion patterns (diagnostic of the precursor syntaxial overgrowth origin). This insensible passage between parts of crystals having apparently both primary and secondary fabrics precludes a neomorphic interpretation for those parts exhibiting "secondary" characteristics (see Kendall and Broughton, 1978, and Broughton, 1983a). This gradational transition has not been observed for aragonite mosaics. On the other hand, aragonite crystals tend to terminate with quadratic faces in association with an iron oxide (or other oxides and organics) impurity layer. This suggests that precipitation of randomly oriented seed crystals on an impurity-rich growth surface (where the lattice continuity with the substrate is not possible) favours the aragonite polymorph.

Aragonite is more suitable to such growth surfaces than calcite because of this polymorph's tendency towards split-growth in acicular, crystals (Fig. 2). Such a divergent growth mechanism rapidly alters the randomly oriented seed crystals mo-

Figure 2. Scanning electron micrographs (centre and upper right) illustrating a moderately packed fabric of fibrous parent and daughter subcrystals in a stalagmite from Wyandotte Caverns, Indiana. Some of the areas exhibit crystal splitting (arrow, centre figure), but most spaces are probably infilled by subcrystals originating as incipient precipitation in an impingement fabric. The crystal boundaries are planar and oriented in manners diagnostic of competitive growth. The lower right figure is a cross section of the specimen, plane polarized light, illustrating additional characteristics suggested to be the result of a primary fabric arising from competitive growth. The fibrous crystals are arranged in fan-shaped sprays that originate at regularly spaced sites (open arrows) above layers of impurities (closed arrows). The divergent acicular sprays arise from aggregates of randomly oriented crystallites at the nucleation sites (at open arrows). Bar scales are 20 microns (centre) and 5 microns. 

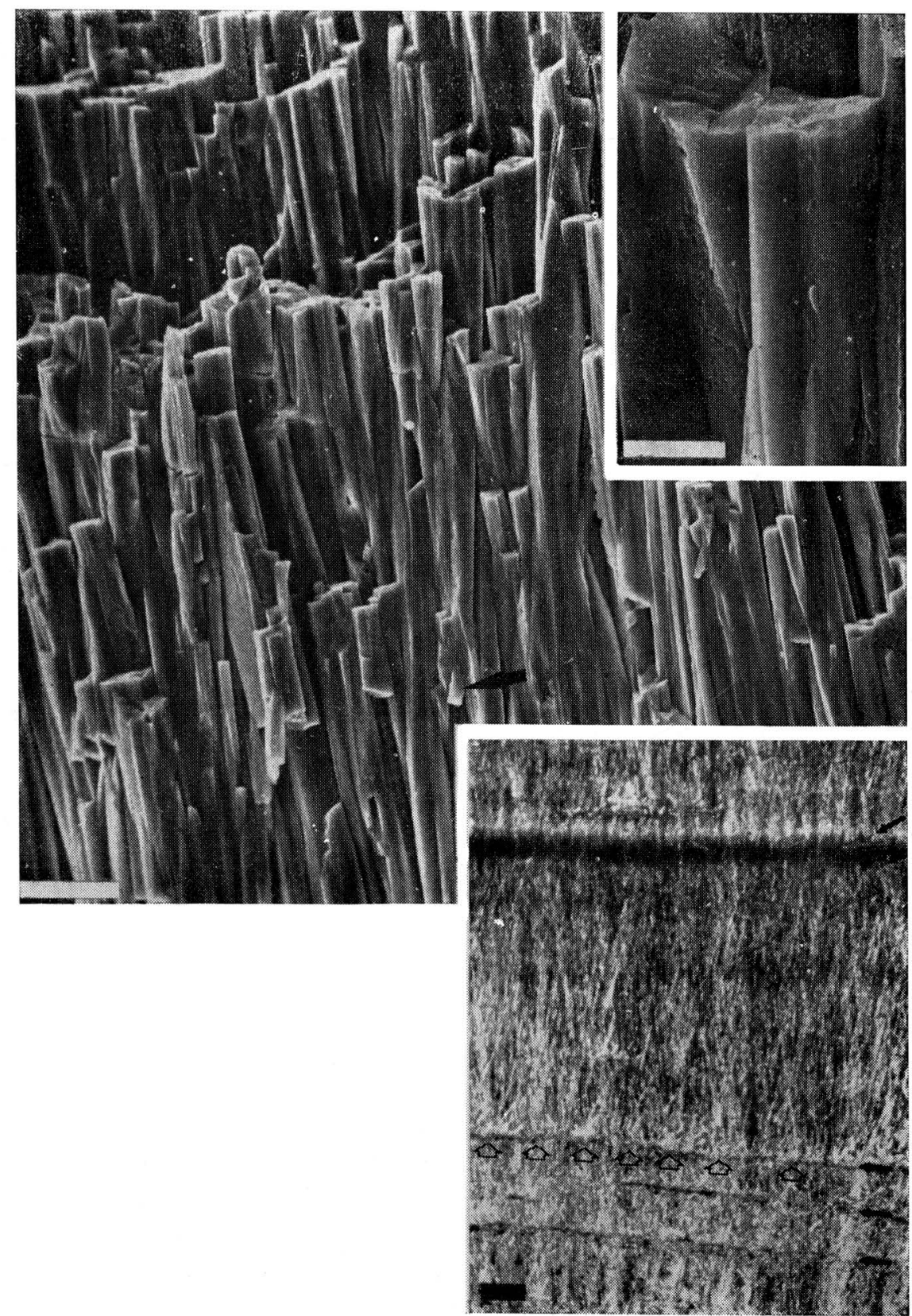
saic into an organized array of fibrous growth centers as in Figure 2.

It is not entirely clear why split-growths with parent-daughter subcrystal relationship, and lack of intervening trapped fluids, do not ultimately coalesce. This is despite an implied lattice continuity and adequate supply of carbonate to the growth surface. Coalescence can be reasonably expected to occur only when the crystallographic axes (a-axis in calcite, a-and b-axes in aragonite) are parallel or sub-parallel. Spherulitic aragonite (Fig. 1) bundles do not contain linear inclusions suggesting coalescence, unlike normal (secondary) growth of acicular calcites. This may be explained by having a sufficient portion of inter-crystallite spaces as sites of incipient fibrous crystals nucleation whose c-axes are oriented parallel to the parent subcrystals, but whose other crystallographic orientations have mismatshed lattices. Any crystals, of whatever composition, if allowed to grow continuously between similarly oriented neighbors will assume a fibrous habit. The fibrous habit merely indicates crystal growth wes free of significant interruption (an impingement fabric). Fibrous calcite and aragonite crystals invariably lack inclusion-defined growth layers, and therefore not subjected to numerous interruptions in their growth. It is not necessary to correlate extreme calcite crystal elongation seen in some growth layers with a high magnesium content nor with deposition from waters with high $\mathrm{Mg}$ :Ca ratios.

Crystal-splitting is suggested to be an important mechanism for divergent growth, but not the principal mechanism. If the divergent or spherulitic growth was dominated by split-growth, then the bundle would have the crystallographic properties of a single crystal. Upon coalescence, this would have the optic properties of fascicular-optic crystals (Kendall, 1977), and recognizable as a secondary fabric by its undulose extinction.

\section{COMPETITIVE GROWTH AND DEPOSITIONAL ENVIRONMENT}

Normal stalactitic carbonate precipitation is from a thin film of water that flows over the growth surfaces. The precursor crystallite overgrowths that coalesce into larger columnar crystals are stable only under this condition. If large crystal terminations were developed on the columnar crystals, they would form projections on the stalactite surface and significant departures may result from the optimum water-shedding properties of the conical to cylindrical form. Water diverted around the crystal terminations would inhibit their growth relative to 
other parts of the surface. The projections would be thus gradually eliminated. With increasing film thickness, however, it is to be expected that larger crystallites could be formed by mergence of the smaller without significantly disturbing the water-film flcw. Under these normal cave conditions, secondary columnar crystals are favoured. However, as soon as the film is disturbed as during a cave flood, new environmental conditions assert competitive growth between the crystal terminations. Larger crystal terminations appear to develop only when the stalactite or stalagmite is immersed. Such faces would grow planar competitive boundaries between adjacent columnar crystals.

Normal growth (syntaxial overgrowths) may be disturbed by markedly diminished, or cessation, of carbonate precipitation during periods of voluminous impurity influx (iron oxides, organics, etc.). This prevents renewed carbonate precipitation from having crystallographic allegience with the substrate and precludes formation of syntaxial overgrowths. Competitive growth between randomly oriented seed crystals is the consequence. Intermittent, and even weaker, pulses of detritus onto the growth surfaces tend to prolong competitive growth. Such environments appear to favour successive fibrous aragonite layers in contrast to formation of acicular calcite fabrics.

\section{CONCLUSIONS}

Competitive growth is suggested to be a relatively rare growth mechanism for interpreting the origin of stalactitic carbonate fabrics. Normal radial growth of columnar crystals has been demonstrated to be a secondary fabric arising from the coalescence of numerous syntaxial overgrowth crystallites. Competitive growth fabrics, in contrast, are generally recognized by such characteristics as decreasing number of crystals in the growth direction and an increasing perfection of the preferred dimensional and crystallographic orientation of crystals away from the layer's origin. Competitive growth is the consequence of two contrasting depositional environments: cessation of carbonate precipitation with the accumulation of a thick layer of impurities (iron oxides, organics, etc.), and conditions of cave flooding which suppress formation of syntaxial overgrowths and favour larger planar crystal terminations. Deposition of randomly oriented seed crystals from which competitive growth centers may arise is generally above layers of impurities thick enough to prevent crystallographic allegiance of the renewed 
growth with the substrate. Such a competitive growth fabric is frequently characterized by an ordered array of favoured growth centers that result in fibrous to bladed acicular crystal aggregates (often spherulitic) divergent away from the growth origin. Fibrous aragonite appears to be the favoured polymorph following periods of growth cessation, whereas the larger planar-faced calcite terminations are more common as a competitive growth fabric during conditions of very thick water film or cave flooding. Aside from these two environmental extemes, normal radial columnar crystal fabrics are formed as a secondary fabric by coalescence of precurscr syntaxial over. growth crystallites, and competitive crystal growth is suppressed. It may however, be difficult to distinguish the primary fabric arising from competitive growth from a neomorphic fabric without a conspicuous relationship to inclusion-defined original fabrics. Without such additional evidence, a portion of a stalactite composed of a randomly oriented mosaic of calcite crystals may be a replacement of layers of fibrous aragonite.

\section{ACKNOWLEDGMENTS}

This paper arises from an earlier study of vadose carbonate fabrics in collaboration with A.C. Kendall, presently at Sohio, San Francisco, California.

The use of research facilities at the Saskatchewan Geological Survey, Regina, and the Department of Geology, University of Cambridge, is acknowledged The author wishes to thank many members of the National Speleologi cal Society, many of whom wish to remain anonymous, for providing the many specimens upon which this study was based.

\section{REFERENCES}

BATHURST R.G.C., 1964. The replacement of aragonite by calcite in the mollusc shell wall. In Imbrie, John and Newell, N.D., (eds.) Approaches to Paleoecology, John Wiley and Sons, New York, N.Y., p. 357-376.

BATHURST R.G.C., 1971. Carbonate Sediments And Their Diagenesis (Developments in Sedimentology, 12), Elsevier, Amsterdam, 620 p.

BROUGHTON P.L., 1983a. Secondary origin of the radial fabric in stalactitic carbonate. Int. Jour. Speleo., (this issue).

BROUGHTON P.L., 1983b. Lattice deformation and curvature in stalactitic carbonate. Int. Jour. Speleo., (this issue).

BROUGHTON P.L., and A.C. KENDALL. 1975. The genesis of some stalactitic crystal fabrics and their relevance to the origin of limestone cements. Geol. Soc. America, Program with Abstracts, 7:1010-1011.

BUCKLEY H.E., 1951. Crystal Growth, Wiley, New York, N.Y., 571 p.

KENDALL A.C., 1977. Fascicular-optic calcite: a replacement of bundled acicular carbonate cements. Jour. Sedim. Petrol.. 47:1056-1062. 
KENDALL A.C. and P.L. BROUGHTON, 1977 Discussion, calcite and aragonite fabrics, Carlsbad Caverns. By R.L. Folk and Riccardo Assereto, Jour. Sed. Petrology, v. 46, p. 486-496: Jour. Sedim. Petrol., 47:1397-1400.

KENDALL A.C. and P.L. BROUGHTON, 1978. Origin of fabrics in speleothems composed of columnar calcite crystals. Jour. Sedim. Petrol., 48:519-538.

MOORE G.W., 1962. The growth of stalactites. Bull. Natl. Speleo. Soc., 24: 95-108.

PRINZ A., 1906. Les cristallisations des grottes de Belgique. Nouv. Mom. Soc. Belge Geol., p. 1-90. 